\title{
Dietitians and Nutritionists Behaviour on Social Media: A Scoping Literature Review
}

\author{
Inga Saboia ${ }^{1,2}$, Ana Margarida Pisco Almeida ${ }^{2}$, Pedro Sousa ${ }^{3,4}$ and Cláudia Pernencar ${ }^{5,6}$ \\ ${ }^{1}$ UFC Virtual, Federal University of Ceará, Brazil \\ ${ }^{2}$ Department of Communication and Art/DigiMedia, University of Aveiro, Portugal \\ ${ }^{3}$ Center for Innovative Care and Health Technology (ciTechCare), Polytechnic Institute of Leiria, Portugal \\ ${ }^{4}$ Health Sciences Research Unit: Nursing (UICISA: E), Nursing School of Coimbra (ESEnfC), Portugal \\ ${ }^{5}$ NOVA Institute of Communication (ICNOVA), Faculty of Human and Social Sciences, New University of Lisbon, Portugal \\ ${ }^{6}$ Arts and Design Research Lab (LIDA), Polytechnic Institute of Leiria, Portugal
}

Keywords: Dietitian, eHealth, Facebook, Instagram, Nutritionist, Social Behaviour, Social Media, Twitter.

\begin{abstract}
At its present state, Social Media (SM) is an important stage to promote user participation, acting as an open space for the discussion of a multitude of fields, one of which being health. Professionals, like Registered Nutritionists and Dietitians (RNDs), whose access to media was traditionally more restricted, are also more engaged in this new context, creating a new scenario. To better understand how is this group of professionals using social media to communicate with their audiences is the main objective of this study. To approach this topic, a mapping was conducted, followed by a presentation of the summary of the evidence discovered: RDNs demographic and professional profile; their most used social media tools; the reasons why they use social media; their common behaviours and attitudes, as well as a review of the gaps and shortcomings in the literature. A literature review, using a structured approach was also conducted. 2877 works were screened, but only 8 were associated with answers. Of these 8 , there were 2 studies that partially presented a quantitative analysis. Results show lacks in consolidated studies that can be used to support the creation of knowledge in this field. This lead to conclude that research about social media usage by nutritionist, at present, remains in a nascent stage and requires further studies.
\end{abstract}

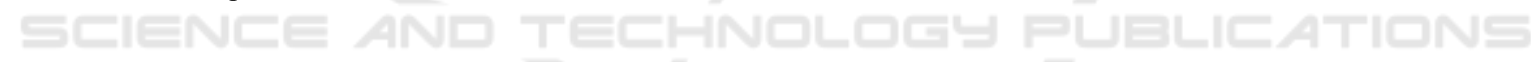

\section{INTRODUCTION}

There is new potential emerging through the connection between Health and Technology, e.g., eHealth (Kreps \& Neuhauser, 2010). In this context, changes in user behaviour are occurring, the users are more active on the online content search and content creation (Sarasohn-Kahn, 2008). Social media is an open field where, currently, the users are able to communicate and actively create content. Nowadays, many users can easily produce high-quality content without being multimedia experts. Nutrition is one of the professions where this aforementioned change occurs, and it has been observed as an "object" of study (Saboia, Pisco Almeida, Sousa, \& Pernencar, 2018).

According to the practice paper of the American Academy of Nutrition and Dietetics wrote by Helm and Jones (2016), RDNs have discovered new strategies for communicating and identified new spaces to spread their ideas. People within this profession are often active participants on social media, and use it as an opportunity to interact with the public. This behaviour is vital for their brand promotion; to advise people; to help their colleagues; to grow business; to support products and services and spread public health campaigns.

With this in mind, it is worth emphasising that the culture of nutritional science is growing and may influence food meanings and eating practices (Dodds \& Chamberlain, 2017). This is due to the fact, nutrition-specific language appears on several kinds of media and not only on social networks, e.g., blogs (Bissonnette-Maheux et al., 2015) and magazines (Dodds \& Chamberlain, 2017). Through these opportunities, RDNs have a space to defend the "right way of eating" based on their scientific knowledge.

In parallel, healthy eating is a topic that is gaining visibility in social media, due not only to content created by RDNs, but also that by Patient Opinion Leaders and Healthy Lifestylers (Saboia et al., 2018). This is particularly relevant, as content from the latter has be documented to potentially instigate negative consequences on the body image of the audience and 
can be linked to several eating disorders (Holland \& Tiggemann, 2017; Koven \& Wabry, 2015).

Helm and Jones (2016) recommend a list of guidelines based on two levels for RDNs. The first level is about following professional standards that refer to a range of principles that should be developed, such as ethics, privacy, confidentiality and reliability. The second level outlines best practices to improve the performance of these professionals on social media. Through this list, the participation and engagement of RDNs on social networks are encouraged. These authors hold that RDNs are the voice of science regarding nutrition. Because of this, it is necessary that these professionals keep a strong position and a clear behaviour when they provide information that are valid and trusted.

Other studies describe that a growing number of RDN is using social media to complement their professional practice aiming to promote business and achieve more customers (Helm \& Jones, 2016; Saboia et al., 2018). Although these studies did not report much detail about the current scenario in terms of quantitative data, this could be considered as an interesting phenomenon. Little is known in this field, despite some observations and guidelines targeting RDNs posture on social media.

It is under this context that the research presented in this paper explores two questions: (i) whether there are studies that analyse the role of RDNs on social media for professional purposes; (ii) how RDNs are using digital media to communicate professionally with the public, analysing how they are acting in social media for their daily professional practices and how they are using digital media field to communicate, professionally, with their public.

One of the most significant findings that emerged during the search process and contribute to carry out this current literature review was Dumas et al. (2018) study, because it showed similar research concerns.. Besides that, they invite, in their future works, other researchers to analyse the theme, stating that "research on social media in dietetic practice is at its infancy". It is worth to clarifying that their investigation did not answer to the main question of the present work, because they do not include statistical data representing this reality.

\footnotetext{
${ }^{1}$ The search on Scielo was also conducted using Portuguese Keywords: "media social" "mídia social" OR "media digital" "mídia digital" OR "facebook*" OR "instagram*" OR "rede social" OR "twitter*") and ("nutricionista" OR "dieticista") without range date.

${ }^{2}$ Nutrícias (https://www.apn.org.pt/ver.php?cod=0E0A0D) e Acta Portuguesa de Nutrição (http://actaportuguesadenutricao
}

\section{METHOD}

A literature review was carried out on the main scientific databases, using a structured approach. This approach is based on a scoping review method that follows these steps:

(1) Delimitation of the research question;

(2) Source definition (scientific database and grey literature);

(3) Establishing relevant keywords and range date;

(4) Selection of eligible studies;

(5) Collating, analysing, summarizing, and reporting results;

(6) Data representation using graphics and tables;

(7) Dissemination of the study.

The main research question of how RDNs are using digital media to communicate with the public explores the topic at a high level. This topic can be broken down further to explore more detailed questions:

- Which RDN profiles are using social media in their dietetic practice?

- Which digital tools have been used in their practice?

- What are the purposes of their use?

- Which are their most common online behaviours?

- What attitudes do RDNs have on digital media?

To understand the professional dietetic practice on social media, a literature review was undertaken.

The set up used was based on the following databases: Cochrane library, Medline, PsyInfo, PubMed - PMC (569), Scopus (46), Web of Science (2214) and Scielo (0)1. Besides that, reference lists of the selected works were consulting in order find out other interesting studies.

In addition to this initial search of scientific databases, the research extended to grey literature like sites, journals and conferences of professional Nutritionists Orders and Associations from Brazil and Portugal $^{2}$. The decision to select these two countries was based on the fact that a study was found exploring RDNs' social media use for communicating with general users (Saboia et al., 2018).

The following keywords arrangement were used: ("nutritionist*" OR "dietician*" OR "dietitian*") AND ("social media*" OR "digital media*" OR

.pt/) from Portuguese Nutrition Association, Rasbran Journal from Nutrition Brazilian Association (https://www.rasbran.co m.br/rasbran), Nutrire journal from Eating and Nutrition Brazilian Society (https://www.springer.com/medicine/interna 1/journal/41110) Accessed in October, $3^{\text {rd }}, 2019$ 
"Facebook*" OR "Instagram*" OR "online network*" OR "social network*" OR "twitter*"). The initial search and screening was limited by title, abstract and keyword fields.

The selection process involved all scientific articles that followed the Prisma methodology (Moher, Liberati, Tetzlaff, Altman, \& Group, 2009) and included diagrammatical representation with distinct phases (fig. 01). This procedure contains criteria for inclusion and exclusion as described below:

The inclusion criteria applied were the following:

- Studies published between 2013 and 2018;

- International conference proceedings and journal articles, both with peer-review;

- English or Portuguese written;

- Works based on RDN's perspectives, stating concrete evidence to show that they are one of the main social media users. To be considered as a user, they should produce content. i.e. when they are posting or sharing;

- Reporting which describes real use scenarios of social media, by presentation of descriptive methods (Dumas et al., 2018), e.g., literature reviews, surveys, interviews and content analysis or expert opinions considered by Dumas et al. (2018).

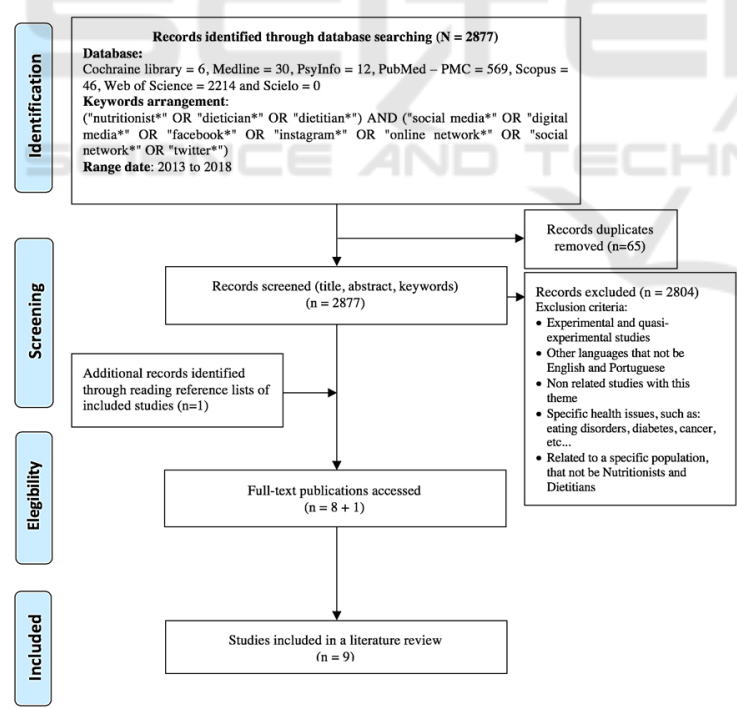

Figure 1: Literature review diagram - PRISMA (Moher et al., 2009).

The exclusion criteria to exclusion were the following:

- Duplicated works;

- Studies that included specific health issues, such as eating disorders, diabetes, cancer, and others;

- Work related to a specific population groups, e.g. pregnant, adolescents, older people, and others.
- Social media users that were not RDNs;

- Studies not describing Social Media usage in real scenarios, like: experimental and quasiexperimental, randomized controlled trial or pilot studies.

\subsection{Categories of Analysis}

The analysis was completed in two phases. First, to enable the comprehension of the general characteristics of the studies, a mapping was conducted following a formal approach and using a grid with several categories (tab. 1):

(1) Year of publication;

(2) Country of authors' origin;

(3) The method used by researchers;

(4) Sample size in different types of information relating to the object of study;

(5) Aim of the study (Dumas et al., 2018);

(6) Type of users (this work prioritises studies describing Dietitians and Nutritionists as users of social media. However, it also includes other kinds of users (Dumas et al., 2018).

During a second phase, the analysis was structured according to the objectives of this study. Specific categories were created:

(1) RDN profile - gender, age, area of speciality, and year of graduation. This category answers the question "Which RDN profiles are using social media in their dietetic practice?".

(2) Social media - as described in previous works (Dumas et al., 2018) this category intend to explore the question "Which digital tools have been used on their practice?"

(3) Purposes of social media use (Dumas et al., 2018) - For this category the researchers aimed to answer the following question "What are the purposes for using it?"

(4) RDN Behaviours - aiming to identify the online behaviours already described by other studies (Kietzmann, Hermkens, McCarthy, \& Silvestre, 2011), such as production, share, reading of content. Therefore, this answered "Which online behaviours are most common for them on digital media?"

(5) RDN attitudes towards digital media Opinion whether there was any indicator of their judgement about the role of social media. It answered the question "What attitudes do RDNs have on digital media?"

Some categories presented were based on literature review previously defended by Dumas et al. (2018). 
Table 1: Summary of the studies found -8 primary sources and 1 secondary (Appetite Communications \& Dietitian Connection, 2018).

\begin{tabular}{|c|c|c|c|c|c|c|}
\hline Study & Year & Country & Method & $\begin{array}{l}\text { Sample } \\
\text { size }\end{array}$ & Type of users & Aim of study \\
\hline $\begin{array}{l}\text { Dumas et al. } \\
\text { (2018) }\end{array}$ & 2018 & Canada & $\begin{array}{l}\text { Literature } \\
\text { review with } \\
\text { formal } \\
\text { approach } \\
\end{array}$ & 47 papers & $\begin{array}{l}\text { Several target } \\
\text { population }\end{array}$ & $\begin{array}{l}\text { Map the evidence about the users, } \\
\text { their uses and effects of social } \\
\text { media in dietetic practice }\end{array}$ \\
\hline $\begin{array}{l}\text { Appetite } \\
\text { Communications } \\
\text { \& Dietitian } \\
\text { Connection (2018) }\end{array}$ & 2018 & Australia & $\begin{array}{l}\text { Online } \\
\text { survey }\end{array}$ & $\begin{array}{c}311 \\
\text { RDNs }\end{array}$ & RDNs & $\begin{array}{l}\text { Describe the educational or } \\
\text { professional use of Social Media by } \\
\text { RDNs or student dietitians and } \\
\text { nutritionist (SDNs). }\end{array}$ \\
\hline $\begin{array}{l}\text { Knight, Brown, \& } \\
\text { Reidlinger (2017) }\end{array}$ & 2017 & $\begin{array}{l}\text { UK and } \\
\text { Ireland }\end{array}$ & $\begin{array}{l}\text { Online } \\
\text { survey }\end{array}$ & $\begin{array}{l}1005 \\
\text { RDNs }\end{array}$ & RDNs & $\begin{array}{l}\text { Describe the educational or } \\
\text { professional use of Social Media by } \\
\text { RDNs or SDNs. }\end{array}$ \\
\hline $\begin{array}{l}\text { Helm \& Jones } \\
\text { (2016) }\end{array}$ & 2016 & USA & $\begin{array}{l}\text { Expert } \\
\text { Opinion }\end{array}$ & $\begin{array}{l}\text { Not } \\
\text { referred }\end{array}$ & RDNs & $\begin{array}{l}\text { Provide guidance for potential } \\
\text { applications, best practices, benefits, } \\
\text { and risks. }\end{array}$ \\
\hline $\begin{array}{l}\text { Twynstra \& } \\
\text { Dworatzek (2016) }\end{array}$ & 2016 & Canada & $\begin{array}{l}\text { Experience } \\
\text { report }\end{array}$ & \begin{tabular}{|c|}
48 SDNs \\
per class \\
(maximum) \\
\end{tabular} & RDNs & $\begin{array}{l}\text { Set out which is the SDNs } \\
\text { experience related to Facebook as a } \\
\text { professional communication tool }\end{array}$ \\
\hline $\begin{array}{l}\text { Hand, Kenne, } \\
\text { Wolfram, Abram, } \\
\text { \& Fleming (2016) }\end{array}$ & 2016 & USA & $\begin{array}{l}\text { Content } \\
\text { analysis and } \\
\text { phone } \\
\text { interviews }\end{array}$ & $\begin{array}{l}294 \text { tweets } \\
\text { and } 16 \\
\text { interviews }\end{array}$ & $\begin{array}{l}\text { Physicians and } \\
\text { RDNs }\end{array}$ & $\begin{array}{l}\text { Depict social media health content } \\
\text { and attitude of health professionals } \\
\text { toward the use of social media as a } \\
\text { method to obtain health } \\
\text { information. }\end{array}$ \\
\hline $\begin{array}{l}\text { Mcgloin \& } \\
\text { Eslami (2015) }\end{array}$ & 2015 & Ireland & $\begin{array}{l}\text { Literature } \\
\text { review }\end{array}$ & $\begin{array}{l}\text { Not } \\
\text { referred }\end{array}$ & $\begin{array}{l}\text { Several target } \\
\text { population }\end{array}$ & $\begin{array}{l}\text { Reveal opportunities based on } \\
\text { digital media about dietary } \\
\text { behaviour change. }\end{array}$ \\
\hline $\begin{array}{l}\text { Adzharuddina \& } \\
\text { Ramly (2015) }\end{array}$ & 2015 & Malaysia & $\begin{array}{l}\text { Literature } \\
\text { review }\end{array}$ & $\begin{array}{l}\text { Not } \\
\text { referred }\end{array}$ & $\begin{array}{c}\text { Physicians and } \\
\text { RDNs }\end{array}$ & $\begin{array}{l}\text { Describe possible Facebook } \\
\text { significance for disseminating } \\
\text { information mainly of health theme }\end{array}$ \\
\hline $\begin{array}{l}\text { Harmse \& Retief } \\
\text { (2015) }\end{array}$ & 2015 & $\begin{array}{l}\text { South } \\
\text { Africa }\end{array}$ & $\begin{array}{l}\text { Expert } \\
\text { Opinion }\end{array}$ & $\begin{array}{l}\text { Not } \\
\text { referred }\end{array}$ & RDNs & $\begin{array}{l}\text { Present some marketing and } \\
\text { business skills to deal with social } \\
\text { media }\end{array}$ \\
\hline
\end{tabular}

\section{RESULTS AND DISCUSSION}

\subsection{First Phase of Analysis}

The first set of analyses highlighted 2877 results from the scientific database search. From this sample, 9 works were selected. Of these, 8 were considered as primary sources and 1 as an additional study as an expert opinion (Dumas et al., 2018). The other search phase, which included a review of grey literature, did not present any results. These evidences were laid out in table 1.

Further analysis showed that there is a few studies with this focus of research. Interestingly, Dumas et al. (2018) results revealed the same delimitation found by

\footnotetext{
${ }^{3}$ The term "Developed countries" is used to delineate trends in various dimensions of the world economy by United Nations report (2015)
}

the researchers of this article, even though they performed services using a different range date: First, it showed $n=23609$ results, but only 47 work, which corresponded to $0,19 \%$. Secondly, $n=2877$, from where $\mathrm{n}=8$ studies were selected from scientific database, which represents $0,278 \%$ of the total. Contrary to the researcher's expectation, it is possible to conclude that this topic remains largely unstudied.

The reached outcomes showed that this study addresses a recent theme of research: there are no references founded on the range date - the two first years -from 2013 to 2014 . Additionally, the fact that 6 studies came from $U S A=2$, Canada $=2$, Ireland $=2$ and $\mathrm{UK}=1$ suggests that this topic is predominantly an area of interest for more developed countries ${ }^{3}$. 
In summary, the most remarkable studies that were identified in the research were two studies that directly explored RDNs. They provided data and analysis that give an understanding of how RDNs utilise social media for their professional work and the attitudes that they have towards it.

\subsection{Second Phase of Analysis}

This part of the investigation analysed the research questions previously listed. The main results are summarized in the table available for online consultig ${ }^{4}$. Besides finding that the most referred social media tools were Facebook (8), Twitter (5), Instagram (4), LinkedIn (4), Pinterest (4), Blogs (3) and YouTube (2), the most surprising evidence was acknowledging the existence of many crucial gaps for understanding this phenomenon:

- Only one study detailed the RDN profile;

- Most of the studies did not describe on detail the type of usage of social media (findings are mainly limiting their report to associate social media as a communication tool);

- the type of online behaviour carried out by RDNs was not described, i.e. it was not possible to understand if they are posting new contents or sharing other contents;

- Only one study presented a RDN opinion about social media, which is sceptical in relation to the efficiency of social media.

The findings of the second phase provided an opportunity to conclude that, from the 9 initial studies, only 4 are more aligned with the main purpose of this research, to understand how RDNs are using digital media to communicate professionally with the public:

- Dumas et al. (2018) study, revealed to be very important, because it showed to have similar concerns with the current analysis. This study involved a very wide target population and different rage data (2000-2016), while the current study focused on RDNs population and from 2013 to 2018 range date. Besides that, Dumas et al research kept without answer to the main question of the present work.

- Hand, Kenne, Wolfram, Abram, \& Fleming (2016) study clarified the judgement of social media by RDNs

- Two other studies that present numerical dimension related to the context of social media use by RDNs: Appetite Communications \& Dietitian Connection (2018) and Knight et al., (2017).
The results of the involved works are presented in the next sections in the following format: general characteristics about the method used and results; summary of the most relevant conclusion and discussion about it.

\subsubsection{Dumas et al. (2018) Study}

The first work that should be mentioned came from the authors Dumas et al. (2018). They highlighted 23609 studies, and from that, 47 were analysed. Subsequently, this sample was divided into the following categories: (1) intervention studies, (2) descriptive studies, (3) content analysis studies and (4) expert opinion papers (table 2). The last category deals with the opinion of specialists but does not present a numerical dimension of RDNs practice on social media.

Dumas' study prompted a few similar questions, though more generic, than the current study was looking for: "Who is using social media in dietetic practice?" and "What are the purposes of social media in dietetic practice?"

The method used to determine the research choices made by Dumas et al. (2018) involved other different topics. These are: the effects caused by social media during health interventions and the barriers and facilitators that could influence the use of social media? Moreover, their analysis was very broad in scope, because they used more keywords, a bigger range date (2000 - 2016) and different types of social media users.

The way Dumas planned the research and the different objectives and approach used, took the study to focus more on health interventions. The ongoing study confirms the previous findings of Dumas et al (2018): only a few works presented as the RDN as the sole object of or the online content created by them. This whole perspective is displayed in table 2 .

Table 2: "Types of the studies" (Dumas et al., 2018).

\begin{tabular}{|l|c|c|}
\hline $\begin{array}{l}\text { Categories of the } \\
\text { selected article }\end{array}$ & $\begin{array}{c}\text { Number of } \\
\text { studies } \\
\text { founded }\end{array}$ & $\begin{array}{c}\text { Number of studies } \\
\text { presenting social } \\
\text { media content written } \\
\text { by RDNs }\end{array}$ \\
\hline $\begin{array}{l}\text { Interventions } \\
\text { studies }\end{array}$ & 34 & 4 \\
\hline $\begin{array}{l}\text { Descriptive } \\
\text { studies }\end{array}$ & 4 & 1 \\
\hline $\begin{array}{l}\text { Content analysis } \\
\text { studies }\end{array}$ & 2 & 1 \\
\hline $\begin{array}{l}\text { Expert opinion } \\
\text { papers }\end{array}$ & 7 & 7 \\
\hline
\end{tabular}

${ }^{4}$ For further information, please visit this link 
It is worth to emphasising that only one of the studies above depicted a real circumstance where a RDN used Social Media for professional practice - in this particular case, a blog. The study was not considered to be included on the current research because "blog" keyword was included as part of this research.

\section{Summary of the Most Relevant Conclusions of Dumas et al. (2018) Study}

There is a more significant number of expert opinion papers that assume RDNs as a social media user that produces content $(\mathrm{n}=7)$, against the description studies $(\mathrm{n}=1)$, content analysis studies $(\mathrm{n}=1)$, and intervention studies $(n=4)$.

The authors did not find studies focused on information gathering about real dimension of this subject. This means that (i) the RDN profile, (ii) their most used digital tools, (iii) their real purpose of writing on social media, and (iv) their behaviours and attitudes are not well defined yet.

There is an indication of a growing interest among RDNs' participation on social media, demonstrated by the number of opinion papers published by professional associations. These groups are concerned with promoting an ethical and professional practice of social media use by RDNs.

\section{Discussion based on Dumas et al. (2018) Study}

There are more opinions about the correct posture of social media presence of RDNs, rather than scientific studies describing the situation. Indeed, it seems that expert opinions are mostly based on personal experience, not on consolidated studies. One of the gaps identified related to the lack of rigorous information about social media content, because there continues to be a misunderstanding about how millions of users deal with social media tools, such as, Facebook or Instagram. Although the study of Dumas et al. (2018) is exhaustive and has similar questions compared to this work, the initial questions are not yet answered. This demonstrates the real existence of many gaps in the literature.

\subsubsection{Hand, Kenne, Wolfram, Abram, \& Fleming (2016) Study}

This study intended to understand the method for the spread of information to health professionals and patients through social media. For this, it's goals are two-fold; it seeks describe the existing social media content and of the attitude of physicians and RDNs who are concerned with social media use to obtain health information.

Their research was divided into 2 phases: the first involved conducting a content analysis of 294 original tweets to gather information about the type of content, source and target public. The second was based on phone interviews with RDNs and physicians to describe their attitude toward the use of social media to communicate general health information and specific information related to heart failure.

\section{Summary of the Most Relevant Conclusion of Hand, Kenne, Wolfram, Abram, \& Fleming (2016)}

The first phase of content analysis provided the following conclusions: there is substantial information on twitter about heart failure, but there is limited content on nutrition. The study identified the heart failure awareness (56.5\%) and patient support (33.0\%) as two of the most frequently cited topics. The source of this content was predominately "professional, government, a patient advocacy organization, or charity" (40.4\%) and "patient or family" $(37.9 \%)$. It is difficult to specify the frequent target audience for this content.

The conclusions about the interview were that: the participants judge social media as a useful tool to gather professional information and that health professionals are sceptical about the potential of social media for efficient communication with patients. This is due to privacy issues, the difficulty for conveying an individualized message and the judgment that their patients are not used to social media or technology.

\section{Discussion based on Hand, Kenne, Wolfram, Abram, \& Fleming (2016)}

Twitter is not being presented as a tool that is often used for nutrition content. This should be verified on future works. It is interesting to better understand the attitudes of RDN regarding to social media on a more generalized way.

\subsubsection{Knight et al. (2017) Study}

From the works collected, one is very useful in answering the research questions: the study of Knight et al. (2017). This presents results of an online survey with 1005 responses of 753 RDNs and 252 SDNs from UK and Ireland. These participants considered themselves as users of social media ( $80 \%$ of RDs and $96 \%$ of SDs). These $45 \%$ of SDs used social media for educational objectives and $41 \%$ of RDs used it for professional goals. Moreover, $66 \%$ of them agreed that 
social media engagement is essential for RDNs to promote their profession. However, $36 \%$ of respondents were concerned that social media use by RDNs could undermine the public's confidence in their activity.

Despite these important results, one important point is missing on this study: distinct results for each type of social media. Social media is seen as a single whole. As a result of this, it is not possible to understand which form of social media is most used, for instance.

\section{Summary of the Most Relevant Conclusion of Knight et al. (2017) Study}

This study argued that RDNs and the students in this field are high users of social media. It also alleged that this group is engaged with social media in their professional lives. One point this study concerns itself with is the negative consequences for their profession that could be caused by inappropriate use of social media. The authors recommend the development of guidelines and training to improve the opportunities and to manage bad results.

\section{Discussion based on Knight et al. (2017) Study}

These authors present the numeric dimension of the reality of RDNs using social media for their professional life. It is missing more detailed information on what RDNs uses are, such as their profile, the most used social media, their reason to use, their common behaviour and attitudes.

\subsubsection{Appetite and Dietitian Connection Report}

The study, $A$ "healthy diet" of social media: Trends in dietitians' social media habits (2018), was included in this research due to the affinity with the initial questions and their findings in numeric results.

It is worth clarifying that it was a secondary source that was found through reading the reference list from Dumas et al. (2018). Another important point to consider is that this study has not been included in the literature review list from Dumas et al. (2018). Perhaps, this differentiation is caused by the source's type of origin, which is more professional rather than academic in nature. Additionally, Dumas et al. (2018) referred to a report from 2016, but our study is based on a more current report from 2018.

This report is based on an online survey that was sent to approximately 6.600 professional, of which 311 completed the questions. This study examined important aspects such as: a) How, when, where RDNs use social media, b) Their preferred social media platform, c) Their purpose of use, d) What information are most sought by them on social media.

\section{Summary of the Most Relevant Conclusion of Appetite and Dietitian Connection Report}

This study highlighted some aspects of object of this study: almost all respondents accessed social media for personal and professional purposes (95\%). RDNs frequently check social media each day ( 8 in 10 checked 4 times a day). The average age of the most part of respondents is less $40(78 \%)$. Five years is the average length of a university degree course (51\%). There are two main areas of speciality: hospital and private practice (respectively $29 \%$ and $22 \%$ ).

More than half respondents have a social media page for professional reasons (54\%). The most used platform is Facebook for personal reasons $(97 \%)$, but LinkedIn is most used for professional purposes, followed by Instagram and then Facebook. Instagram's popularity is increasing. Participants' usage of Instagram has increased over the last 4 years (about $22 \%$ ); nearly half of RDNs use Instagram for professional purposes. RDNs are leaving to use blogs, YouTube and Twitter.

\section{Discussion based on Appetite and Dietitian Connection Report}

This study has many pros and cons. At one hand, it identifies important points relating to the research questions. In this case, it represents the RDNs profiles, their habits of use, their most preferred platforms, and behaviours and attitudes associated with social media.

On the other hand, this work demonstrates how important social media is for RDNs' life. They describe the RDNs' profile that uses social media. It identifies the leading social media platforms that have been used (Facebook, Instagram and LinkedIn). Unfortunately, this study requires a more theoretical and methodological grounding because it is a professional report that uses only a small sample from within the area of RDN (311 respondents). Aside from this, the nature of this sample could be biased, because the respondents are into this universe of people that assume themselves as RDN and who are registered on newsletter list of the company's site. Moreover, the reality described is related to one country, Australia. 


\section{FINAL CONCLUSIONS, FUTURE WORKS AND LIMITATIONS}

The mapping described in this paper demonstrated the potential of the object of study: a small number of researches was gathered. More research is needed to better understand RDNs practices on social media. There are also missing points to answer the initial question "how are RDNs using digital media to communicate with their public?". Both the literature review and the analysis by Dumas et al. (2018) underline this gap. One of the main conclusions is, therefore, the need to deep knowledge about RDNs contexts and attitudes related to social media, such as: their profile, the most used social media, their reason to use, and their common behaviour and attitudes.

This theme should be explored in more detail, and its study should be continued through conception, planning and submission of a survey for a RDNs database. Their objective could be to understand how RDNs are using social media to communicating with an audience on commercial social media with millions of users.

In addition, it is recommended that other researchers, namely the ones from the social media field, may approach this topic by choosing to analyse the social media tools more used by RDNs (Appetite Communications \& Dietitian Connection, 2018).

This study also has some limitations, it is possible that there are missing works in this review, because: the range date and the keywords arrangement were very restricted; therefore future studies are needed to search for bigger period (than January 2013 to July 2018) and for more strings.

\section{ACKNOWLEDGEMENTS}

This work has been supported by Fundação para a Ciência e a Tecnologia (FCT), from the Ministério da Ciência, Tecnologia e Ensino Superior (MCTES) and from European Union through Programa Operacional Capital Humano $(\mathrm{POCH})$, funded with the grant $\mathrm{n}^{\mathrm{o}}$. SFRH/BD/137451/2018.

\section{REFERENCES}

Adzharuddina, N. A., \& Ramly, N. M. (2015). Nourishing healthcare information over Facebook. Procedia - Social and Behavioral Sciences, 172, 383-389. https://doi.org/10.1016/j.sbspro.2015.01.384
Appetite Communications, \& Dietitian Connection. (2018). A "healthy diet" of social media: Trends in dietitians' social media habits. Retrieved from https://appetite communications.com.au/wp-content/uploads/2018/12/2 018 dieticians_social_media_usage_report.pdf

Bissonnette-Maheux, V., Provencher, V., Lapointe, A., Dugrenier, M., Dumas, A.-A., Pluye, P., ... Desroches, S. (2015). Exploring Women's Beliefs and Perceptions About Healthy Eating Blogs: A Qualitative Study. Journal of Medical Internet Research, 17, 1-13. https://doi.org/10.2196/jmir.3504

Dodds, A., \& Chamberlain, K. (2017). The problematic messages of nutritional discourse: A case-based critical media analysis. Appetite, 108, 42-50. https://doi.org/10.1016/j.appet.2016.09.021

Dumas, A., Lapointe, A., \& Desroches, S. (2018). Users , Uses, and Effects of Social Media in Dietetic Practice: Scoping Review of the Quantitative and Qualitative Evidence. Journal Of Medical Internet Research, 20(2), 1-17. https://doi.org/10.2196/jmir.9230

Hand, R. K., Kenne, D., Wolfram, T. M., Abram, J. K., \& Fleming, M. (2016). Assessing the viability of social media for disseminating evidence-based nutrition practice guideline through content analysis of twitter messages and health professional interviews: An observational study. Journal of Medical Internet Research, 18(11). https://doi.org/10.2196/jmir.5811

Harmse, B., \& Retief, I. (2015). Striving for excellence: Investigating the practical aspects of dietetic practice. South African Journal of Clinical Nutrition, 28(2), 8991. https://doi.org/10.1080/16070658.2015.11734537

Helm, J., \& Jones, R. M. (2016). Practice Paper of the Academy of Nutrition and Dietetics: Social Media and the Dietetics Practitioner: Opportunities, Challenges, and Best Practices. Journal of the Academy of Nutrition and Dietetics, 116(11), 1825-1835. https://doi.org/10.1016/ j.jand.2016.09.003

Holland, G., \& Tiggemann, M. (2017). "Strong beats skinny every time": Disordered eating and compulsive exercise in women who post fitspiration on Instagram. International Journal of Eating Disorders, 50(1), 76-79. https://doi.org/10.1002/eat.22559

Kietzmann, J. H., Hermkens, K., McCarthy, I. P., \& Silvestre, B. S. (2011). Social media? Get serious! Understanding the functional building blocks of social media. Business Horizons, 54(3), 241-251. https://doi.org/10.1016/j. bushor.2011.01.005

Knight, A., Brown, F., \& Reidlinger, D. (2017). Social media use by registered dietitians and pre-registration dietetic students in the UK and Ireland. In Proceedings of the Nutrition Society (Vol. 76, p. 2017). https://doi.org/10.1017/S00296651 17003792

Koven, N. S., \& Wabry, A. (2015). The clinical basis of orthorexia nervosa: emerging perspectives. Neuropsychiatric Disease and Treatment, 11, 385-394. https://doi.org/10.2147/ NDT.S61665

Kreps, G. L., \& Neuhauser, L. (2010). New directions in eHealth communication: Opportunities and challenges. 
Patient Education and Counseling, 78(3), 329-336. https://doi.org/10.

1016/j.pec.2010.01.013

Mcgloin, A. F., \& Eslami, S. (2015). Digital and social media opportunities for dietary behaviour change Proceedings of the Nutrition Society. In Conference on 'Changing dietary behaviour: physiology through to practice Symposium 3: Novel methods for motivating dietary change (pp. 139-148). https://doi.org/10.1017/S0029665 114001505

Moher, D., Liberati, A., Tetzlaff, J., Altman, D. G., \& Group, T. P. (2009). Preferred Reporting Items for Systematic Reviews and Meta-Analyses: The PRISMA Statement. PLoS Med. https://doi.org/10.1371/journal.pmed 1000097

Saboia, I., Pisco Almeida, A. M., Sousa, P., \& Pernencar, C. (2018). I am with you: a netnographic analysis of the Instagram opinion leaders on eating behavior change. Proceedings CENTERIS 2018 - International Conference on ENTERprise Information Systems / ProjMAN 2018 - International Conference on Project MANagement / HCist 2018 - International Conference on Health and Social Care Information Systems and Technologies, , 97-104. https://doi.org/10.1016/j.procs. 2018.10.014

Sarasohn-Kahn, J. (2008). The Wisdom of patients: health care meets online social Media. Oakland: California HealthCare Foundation.

Twynstra, J., \& Dworatzek, P. (2016). Use of an Experiential Learning Assignment to Prepare Future Health Professionals to Utilize Social Media for Nutrition Communications. Canadian Journal of Dietetic Practice and Research: A Publication of Dietitians of Canada = Revue Canadienne de La Pratique et de La Recherche En Dietetique : Une Publication Des Dietetistes Du Canada, 77, 30-34. https://doi.org/10.3148/cjdpr-2015-032

United Nations. (2015). Country classification. Retrieved October 1, 2019, from https://www.un.org/en/ development/desa/policy/wesp/wesp_current/2014wesp _country_classification.pdf 